Policy Contribution Issue $\mathrm{n}^{\circ} 17$ | October 2018

\title{
Should we give up on global governance?
}

\author{
Jean Pisani-Ferry
}

\section{Executive summary}

\section{JEAN PISANI-FERRY}

(jean.pisani-ferry@eui.

eu) European University Institute, Bruegel, Hertie

School of Governance and Sciences Po.

This paper, which partially draws on my Tommaso Padoa-Schioppa inaugural lecture at the EUI, is an updated and augmented version of a contribution to the Hertie School's Governance Report 2018, published under the title 'Is global governance passé?' It owes to stimulating discussions with George Papaconstantinou and the participants in seminars at the EUI, LUISS, Bruegel, the Blavatnik School of Governance, the Brookings Institution and the Peterson Institute. I am also indebted to comments from Marek Dabrowski, Francesco Papadia, Manuel LafontRapnouil and Guntram Wolff. Support by Mercator Stiftung is gratefully acknowledged.

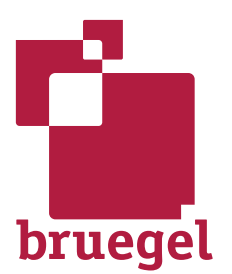

THE HIGH POINT of global governance was reached in the mid-1990s around the creation of the World Trade Organisation. It was hoped that globalisation would be buttressed by a system of global rules and a network of specialised global institutions. Two decades later these hopes have been dashed by a series of global governance setbacks, the rise of economic nationalism and the dramatic change of attitude of the United States administration. From trade to the environment, a retreat from multilateralism is observable. The 2008 elevation of the G20 to leaders' level was an exception to this trend. But the G20 is no more than a political steering body.

THE REASONS FOR this retreat partially arise from political developments in individual countries. But such factors hide series specific roadblocks to global governance: the growing number and diversity of countries involved; the mounting rivalry between the US and China; doubts about globalisation and the distribution of the associated benefits; the obsolescence of global rules and institutions; imbalances within the global governance regime; and increased complexity.

WHAT, THEN, SHOULD be the way forward? The demand for global governance has not diminished, but support for binding multilateral arrangements has. There is a need for alternative governance technologies that better accommodate the diversity of players, provide for more flexibility and rely less on compulsion. From competition to financial regulation, such arrangements have been developed in a series of fields already. They are often hailed as providing a solution to the governance conundrum. But their effectiveness should be assessed critically. Can they overcome the free-rider curse and enforcement problems? Usual game theory suggests not. Not all games are similar, however, and some collective action problems can be tackled without recourse to coercion.

AGAINST THIS BACKGROUND, multilateralists hesitate over the choice of a strategy. One option would be to seek to preserve the existing order to the greatest extent possible. Its downside is that it does not address the underlying problems. An alternative option is to try to redesign international arrangements, putting the emphasis on flexibility and voluntary participation. Its downside is that it risks overlooking the intrinsic problems of international or global collective action. A potentially more promising approach would be to define the minimum conditions that the multilateral framework must fulfil to provide a strong-enough basis for flexible, variable-geometry and possibly informal arrangements.

IN THE END, we should neither cultivate the nostalgia of yesterday's order nor invest our hopes in ineffective international cooperation. The narrow path ahead is to establish a sufficient, critical multilateral base for flexible arrangements and to equip policymakers with a precise toolkit for determining, on a field-by-field basis, the minimum requirements for effective collective action. 


\section{Introduction}

Flash back to 1995. After an eight-decades-long split, the world economy was in the process of being reunified. To manage an ever-growing degree of interdependence, the global community had initiated a process aimed at strengthening the existing international institutions and creating new ones. The World Trade Organisation (WTO) had just been brought to life, equipped with a binding dispute-resolution mechanism that would, among other things, provide an effective channel for managing China's transition from a closed, planned economy to an open economy that plays by the rules of global markets. A new round of multilateral trade negotiations was in preparation. The Multilateral Agreement on Investment (MAI) was being negotiated under the aegis of the Organisation for Economic Co-operation and Development (OECD). The creation of a global competition system was contemplated. The International Monetary Fund (IMF) would soon be given a broader mandate to oversee cross-border capital flows. A legally binding international agreement, the Kyoto Protocol on climate change, was being negotiated, and plans were drawn for an international environment organisation that would provide a fifth pillar to the global order, alongside the WTO, the Bretton Woods institutions, and the (less effective) International Labour Organisation (ILO). There were strong hopes that the institutional architecture of globalisation was being built.

The intended message to the people was clear: globalisation-a new concept at the time-was not just about liberalising flows of goods, services and capital. It was also about establishing the rules and public institutions required to steer markets, foster cooperative behaviour on the part of governments, and manage a single global economy. Global public goods-another new concept that was loosely applied to a series of issues from biodiversity to climate and from public health to financial stability - would be taken care of through jointly agreed rules of the game. The successful Montreal Protocol on eliminating ozone-depleting gases, agreed in 1987, provided an encouraging template.

These claims were not exempt from hype. Liberalisation was real, but the strengthening of the legal and institutional architecture was only in the making. Also, there were problems with the governance of global institutions:

- To start with, Europe, the United States and Japan were not only running the show by participating in the Group of Seven (G7); they were also overrepresented on the boards of the IMF and the World Bank, and they enjoyed disproportionate influence in the other major institutions. There was a clear need to redistribute power and influence in favour of emerging and developing countries, whose weight in the world population and GDP was growing fast;

- Second, governance through sectoral institutions was potentially problematic: each one dealt with one particular field, but none was in charge of cross-sectoral issues such as trade and exchange rates, trade and labour, or trade and the environment (to name just a few). True, the United Nations was meant to provide an overall framework. But in the economic field at least, the UN system was deprived of effectiveness ;

- Third, these institutions were increasingly criticised for being undemocratic because they were accountable only to governments and not to any parliamentary body. Civil society organisations and environmental NGOs were insistently calling for a remedy to these deficiencies. The international institutions were slowly learning to give them a voice.

The way forward looked clear: liberalisation would be pursued further and globalisation would be managed by strengthening and developing a network of global institutions, each of which would take responsibility for one of the main channels of interdependence. The governance of these institutions would be reformed, so that emerging and developing countries would gradually gain power at the expense of the advanced countries. These institutions would cooperate to address cross-sectoral issues and, as a substitute for proper accountability 


\section{Economic nationalism is on the rise. Its offensive guise, state capitalism, is a much more powerful force than anybody expected a quarter of a century ago; it is especially, but far from exclusively, strong in China}

to a non-existing global parliament, they would develop a dialogue with civil society. Some, like Rodrik (1997), doubted this could be a workable solution and highlighted a trilemma between deep integration, national autonomy and democratic governance. But there was hardly another template on offer.

Fast forward now to 2018. Despite more than a decade of discussions, the global trade negotiations launched in 2001 in Doha (known as the Doha round) have not led anywhere. The WTO is still there but on the verge of becoming wholly ineffective. After obstructing the WTO's dispute settlement system by preventing the appointment of new members to its Appellate Body, President Trump declared on 30 August 2018 that the US would pull out of the WTO unless the organisation "shapes up"1. Negotiations over the MAI collapsed in 1998. The Kyoto Protocol was signed, but was not lastingly implemented, largely because the US decided not to ratify it. The 2009 Copenhagen conference on climate change failed to reach agreement on mandatory limits on greenhouse gas emissions and ended in dispute. Less than two years after a general, though non-quantitative and non-binding agreement was reached on the occasion of the 2015 COP21 in Paris, the US announced in June 2017 its withdrawal from it. And nobody talks of a global competition system or a global environmental organisation anymore.

Economic nationalism is on the rise. Its offensive guise, state capitalism, is a much more powerful force than anybody expected a quarter of a century ago. It is especially, but far from exclusively, strong in China where corporate champions that were expected to transform into standard public companies remain under the direct or indirect control of the government. Nearly a decade after China joined the WTO, the balance between state-led coordination and market-led coordination is not at all what it was supposed to be. Contrary to expectations, there is growing fear that the Chinese model of development is diverging from the standard market economy template (Wu, 2016). Policy instruments that China regards as development levers are seen by the US administration as instruments of economic control that distort competition and hurt US interests ${ }^{2}$.

Economic nationalism's defensive guise, protectionism, is especially, but far from exclusively strong in the US where the Trump administration has embarked on a series of ruthless (and fairly incoherent) initiatives against its main trade partners. In trade at least, it has taken the bilateral route and disregards multilateral rules and procedures entirely. Particularly worrying is the fact that the US has used a national security clause in the General Agreement on Tariffs and Trade (GATT) to impose tariffs on imports from its allies and partners. Countries regarded as running excessive bilateral surpluses are being commanded to reduce them without delay. China has been brutally ordered to import more, export less, cut subsidies, refrain from purchasing US technology companies, curtail investment in sensitive sectors and respect intellectual property (US Government, 2018). The very principles of multilateralism, that pillar of global governance, seem to have become a relic from a distant past. The US seems to have reverted to its interwar defiance vis-à-vis the international system.

The retreat of multilateralism is not limited to the trade realm. It is also visible-though much less pronounced-in international finance where three broad trends are noticeable (De Gregorio et al, 2018). First, the IMF's attempt to gain a formal extension of its mandate failed already in 1997 and there has been a move away from across-the-board financial account liberalisation. According to the index built by Fernández et al (2016), average restrictions on financial flows bottomed out in the mid-2000s. Since then, capital controls and other regulatory impediments to free movement of capital have regularly increased. Second, since

1 Interview with Bloomberg, 30 August 2018.

2 According to the US Trade Representative (2018: 17), "a key part of China's technology drive involves the acquisition of foreign technologies through acts, policies, and practices by the Chinese government that are unreasonable or discriminatory and burden or restrict U.S. commerce. These acts, policies, and practices work collectively as part of a multi-faceted strategy to advance China's industrial policy objectives. They are applied across a broad range of sectors, overlap in their use of policy tools (eg the issuance of planning documents and guidance catalogues), and are implemented through a diverse set of state and state-backed actors, including state-owned enterprises." 


\section{Recent developments challenge the system of universal, multilateral, public, treaty- based, institution- supported and legally enforceable rules that provided the basis for global governance since the second world war}

the Asian crisis of 1998, there has been an increasing reliance on unilateral, bilateral or regional solutions rather than on the multilateral safety nets provided by the IMF. National reserves have increased more than tenfold since 2000, against a factor of 3.7 for IMF resources (Truman, 2018). In 2007-08, US dollar swap lines were extended on a strictly bilateral basis by the Federal Reserve to selected central banks; they proved instrumental in avoiding financial disruption but the initial choice of partner central banks and the later decision to grant to some of them permanent access to dollar liquidity have been purely discretionary. Third, regional financing arrangements have developed as a complement but also a potential substitute to the multilateral safety net. Whereas Europe is admittedly a special case because of the introduction of a common currency, the instruments in place could conceivably be used in a broader regional context. Reliance on regional cooperation has also developed in Asia and Latin America.

The trend is similar in relation to the environment. Although the Paris Agreement of December 2015 was hailed as a success of international cooperation, it is far less constraining than the Montreal and Kyoto protocols. Signatories did not commit to internationally determined emission ceilings nor did they subscribe to a multilateral system of rules; rather, each state individually announced what it intended to contribute to the common endeavour, frequently conditional on efforts made by others or on the availability of financial support (Tagliapietra, 2018). There is no enforcement mechanism either. Beyond climate, the failure to address the rapid deterioration of biodiversity illustrates the limits of commitments to collective action to protect the environment.

Cross-sectoral initiatives also cast doubts over the global governance model of the late twentieth century. A puzzling case is the Chinese Belt and Road Initiative (BRI). At one level it can be analysed as a regional infrastructure development endeavour. But it is also presented by Chinese sponsors as a potentially more encompassing project and a "new globalisation mechanism" (Jin, 2018). US critics regard it instead as "debt diplomacy to expand influence" (Pence, 2018). An early test will be provided by the treatment of the bilateral debt overhangs of partner countries. So far, China has been reluctant to contemplate settling overindebtedness cases within the framework of the Paris Club, the usual multilateral venue.

It is hard not to conclude that recent developments in a wide range of fields have dashed the expectations of the 1990s. These developments challenge the system of universal, multilateral, public, treaty-based, institution-supported and legally enforceable rules that provided the basis for global governance since the second world war. The legal and institutional order that underpinned international economic relations for seven decades is undergoing a slow, but major overhaul.

The exception to this trend - admittedly quite a significant one, at first sight at least - has been the creation of the Group of Twenty (G20). At the end of 2008, in response to the Global Financial Crisis, the dramatic decision to establish it (or, more precisely, to elevate an existing finance ministers' body to government leaders' level) suddenly gave emerging countries the voice at the high table they had for many years been asking for. Furthermore, it involved them in the design of a financial and macroeconomic response to the worst crisis in six decades. In Washington in November 2008, the G20 initiated a comprehensive financial reform agenda, the implementation of which would be monitored by a new institution, the Financial Stability Board (FSB) 3 . In London in April 2009, the G20 engineered a concerted budgetary stimulus of an unprecedented magnitude - in which, for the first time ever, the emerging and developing countries participated alongside the advanced countries. In London also, it was decided to increase significantly the resources of the IMF and to proceed with a special one-time allocation of Special Drawing Rights (SDRs), in order to beef up liquidity at the global level. And in Pittsburgh in September 2009, the G20 initiated a Mutual Assessment Process through which

3 The FSB, an assembly of regulatory and financial authorities from G20 and several other countries, was not created ex nihilo but succeeded the previously existing Financial Stability Forum, whose mandate was significantly enhanced. 
the contribution of national policies to the reduction of global imbalances would be regularly monitored by the IMF and discussed among national policymakers ${ }^{4}$. Since then, the G20 has continued to serve as platform for political dialogue and as a steering body for collective initiatives in a variety of fields (Bery, 2018).

The creation of the G20 was initially hailed as a major step forward for global governance. The leaders claimed that "a global crisis requires global solutions" (London Declaration, April 2009), and announced that the G20 would become "the premier forum for international economic cooperation" (Pittsburgh declaration, September 2009). The G20's establishment and first steps marked indeed a major departure from the 'Own House in Order' doctrine that dominated international economic relations in the early 2000s. Because the Global Financial Crisis illustrated that financial stability is a global public good, the provision of which cannot be left to national authorities acting in isolation, it resulted in a major revision of the prevailing international policy doctrine.

But there should be no mistake. The G20 is no international organisation. It is a political institution that works by consensus and steers the work of technical bodies by issuing political guidelines. The technical bodies themselves are not organisations equipped with effective powers, but are mere coordinating forums. To produce results, the G20 therefore relies on its agenda-setting power and a chain of institutions of uneven effectiveness. Its creation was not meant to imply that participating countries intended to strengthen international law and abide by it. And actually they did not: in the financial field, arguably the domain where most efforts were concentrated in the aftermath of the global crisis, the FSB was neither created as a universal institution nor equipped with decision-making or enforcement powers. Its membership comprises 68 institutions, including ministries of finance, central banks and supervisory and regulatory authorities from 25 jurisdictions, as along with 10 international organisations and standard-setting bodies. It is structured as a coordinating platform that promotes, monitors and advises - in other words "orchestrates" the action of independent national and supranational bodies (Abbott et al, 2015). So even in the most active of all fields, a significant departure from the standard model is noticeable.

The G20 furthermore quickly disappointed hopes (or fears) that it would effectively coordinate national economic policies. The Global Financial Crisis was more a high-noon moment than the start of a continuous coordination process. Writing only a few years after the first G20 summit, Angeloni and Pisani-Ferry (2012) already concluded that they were fearful of "diminishing returns". Developments since have not resulted in a revision of this judgement.

\section{Roadblocks to global governance}

While the increasingly adversarial tone of the international discussion owes considerably to the specific stance of the Trump administration, most observers agree that problems began before the 2016 US presidential election. Almost ten years ago, Richard Haass (2010) asserted that multilateralism in the twenty-first century was likely to be more fluid and more messy than it used to be. And five years ago, Hale et al (2013) claimed that the international community was facing a gridlock of global governance; they observed that stalemate had been reached on a number of fronts and that gaps in the system of international relations were not being filled.

What is the reason for this change in the landscape? It would be hard to claim that it is due to diminishing demand for collective action. If anything, the need has increased with integration on a global scale and concerns over global public goods such as climate change mitiga-

4 Angeloni and Pisani-Ferry (2012) provide a critical account of the G20's early initiatives. 
tion, the fight against terrorism, economic and financial stability, or protection against cyberattacks. Citizens worldwide are increasingly conscious of the need for common responses to these global threats to prosperity and security (Pew Research, 2017).

Politics provides a tempting explanation why supply does not meet demand. Already in the 1990s, strong reservations about supranational institutions were regularly expressed by sovereignty- conscious governments and parliaments, starting with the US Congress. Since then politics has moved further in the direction of curtailing the powers of supranational institutions. From the US to Europe and from India to China, nationalism and identity politics are on the rise everywhere. Among "somewhere people", to use Goodhart's (2017) cogent expression, anger against "anywhere people" and especially rootless international bureaucrats has risen dramatically, fuelled by shrewd political entrepreneurs. International civil servants were not loved, but at least they were deemed competent. The global financial crisis has dented this reputation.

From this observation, one might conclude that global rules and institutions are simply caught in a political storm whose roots are much deeper and much more perplexing than anything directly related to the operation and performance of these very rules and institutions. But if politics is changing, broad explanations should not serve as an excuse to not identify more proximate causes. Five major roadblocks hamper the provision of global governance.

\section{A. Geopolitics}

The first reason why global governance is in trouble is of a geopolitical nature: the rules and institutions established in the mid-twentieth century have been questioned by the accelerated change in the balance of economic and political power between the 'West' and the 'Rest'. Specifically, and importantly, US global leadership is increasingly challenged.

Scholars of international relations regard the international liberal order put in place at US initiative after the second world war as a political project as much as an economic one. The global governance regime was conceived in such a way that it would serve as an antidote to war between participating nations and as a glue that would strengthen the Atlantic alliance. The liberal international order, to use the characterisation of Ikenberry $(2015,2018)$ was both multilateral (in that all participants were subject to the same rules) and hegemonic (in that it had been built by and around the US, which as the major power served both as an anchor and as provider of public goods). The core quid pro quo was that the hegemon would both benefit from its central position and accept being significantly (though not entirely) constrained by the multilateral rules, for example international trade rules. In the words of Ikenberry (2018), the US was supposed to behave as the 'first citizen' of that world.

Over the last quarter of century, three transformations have been at play:

- The first has to do with the number of significant participants in the global game. Back in 1990, there were actually few: only the US, Canada, Western Europe, Japan, Australia, South Korea, Taiwan and the oil producers really mattered. One of Olson's rules of thumb for collective action is that size matters and, as it increases, renders cooperation more difficult, an evolution well illustrated by the transition from the G7 to the G20 (Olson 1965; see also Laïdi, 2018);

- The second, related transformation arises from the increased diversity of participants: because international unions result from a trade-off between economies of scale and the heterogeneity of preferences, an increase in the latter is bound to hamper cooperation (Alesina et al, 2005). As developing and emerging countries have grown disproportionately, yesterday's small and relatively homogeneous club has become much more diverse (again, this is illustrated by the G20);

- The third transformation has to do with leadership. Whereas the US briefly emerged in the 


\section{The key geopolitical question for the future is whether an international order can help manage a gradual shift in the power balance between the US and China"}

1990s as the world's 'hyperpower' (to use an expression coined by former French minister Hubert Védrine), its relative military, economic and political weight has diminished over the last quarter of century, while that of Europe has slid at an even faster pace. Because of its scientific, financial and strategic might, the US is still by far the dominant power, but in terms of sheer economic weight, influence and - increasingly - control of critical resources and technologies, China has emerged as a fast-rising rival (Bergsten, 2018). In an unusually harsh speech in October 2018, US Vice-President Pence emphasised that the administration was unwilling to tolerate what he described as hostile Chinese behaviour (Pence, 2018).

The key geopolitical question for the future is whether an international order can help manage a gradual shift in the power balance between the US and China. That there is a demand for it is clear. According to Allison (2017), important "clues" from the analysis of past episodes of rivalry are that "higher authorities can help resolve rivalry without war" and that "states can be embedded in larger economic, political, and security institutions that constrain historically 'normal' behaviours". An international order may therefore help avoid Thucydides' trap - that when one great power faces displacement by another, war is almost always the result. The question, however, is whether such an international order can be sustained. The incumbent leader might regard it as an excessive limitation on the use of its power - something the Trump administration has ceaselessly emphasised - while the rising power might regard rules as excessively determined by the preferences of the incumbent - an opposite concern regularly expressed by $\mathrm{China}^{5}$. In such a case the international order can be a casualty of the confrontation between the incumbent and the rising nations.

China's rise is not the only geopolitical challenge to the US-led international order. Heightened tension with Russia, growing terrorism-related security concerns and increasingly assertive emerging countries have all contributed to changing the global picture. But China's rise is probably the most significant challenge for the medium term.

\section{B. Second thoughts on globalisation}

The second obstacle results from a change in attitudes towards globalisation. Since the 1990s the intellectual and political consensus in favour of economic openness, international integration and the strengthening of international rules and institutions has weakened significantly. It is fair to say that many countries are having second thoughts on globalisation.

Globalisation and its governance are not exactly the same thing. Dissatisfaction with the consequences of the former - because of increased inequality and social dislocation in the advanced countries, and because of the overhaul of traditional markets in the emerging countries - are not necessarily attributable to failures of the latter. Rather, they can be, and frequently are, the consequences of the opening of those sectors previously sheltered from trade and investment flows and of the lack of appropriate domestic policy responses. For an advanced country, opening to trade with less-advanced partners is bound to create losers. To compensate or retrain the losers, or to reform labour, product and capital markets so that they can find opportunities in other sectors, is the task of domestic policies, not of international institutions. For example, the US federal government and national labour market institutions are mostly to blame for the dismal reallocation and redistribution record documented by Autor et al (2013), but unfair foreign competition and the global rules that permitted it are easy to blame. Similarly, the reallocation of factors of production to new sectors is a domestic responsibility in emerging and developing economies. An important reason why global governance is in trouble therefore arises from a backlash against national failures to correct the distributional effects of globalisation within countries.

A more challenging issue analytically is whether the aggregate gains from globalisation have been unevenly distributed among participating countries. The Trump administration's

5 For recent perspectives on China's view of the world, see Rudd (2018) and Wolf (2018). 
basic claim is that the US has been losing out whereas China has gained overwhelmingly from trade liberalisation. Although this an undoubtedly biased assessment, it is indisputable that technology transfers to emerging countries can cost the advanced countries an accelerated erosion of their innovation rent and can result in a net loss for them - a point made by Samuelson (2004) more than ten years ago ${ }^{6}$. By the same token, one of the reasons for the failure of the Doha round has been the perception that developing countries had lost out in the Uruguay round because the resulting agreement committed them to open their services markets but did not give them enough access to the agricultural markets of the advanced countries. Since the mid-1990s, export gains have been very unevenly distributed among developing countries and only a handful of them has experienced industrialisation and a rise in manufacturing exports (Baldwin, 2016). Several other developing and emerging countries have experienced "premature deindustrialisation" (Rodrik, 2015). In such conditions, sustaining an open, non-discriminatory trade regime is politically challenging to say the least.

In the financial field, there has been a major revision of the 1990s consensus on the benefits of opening to capital movements. Whereas the US and a few other advanced countries have been net beneficiaries of the global demand for safe assets (Caballero et al, 2008), many emerging countries have suffered from destabilising capital inflows followed by sudden stops with, as a result, financial crises, IMF programmes, and, ultimately, changes to their financial account regimes.

\section{Obsolescence of global rules and institutions}

Although the previous argument primarily rests on the broad pattern of international trade and finance, the adverse effects of external liberalisation can be compounded by inadequate governance. As far as trade is concerned, two cases in point are, first, inertia in the categorisation of countries, especially the fact that emerging countries, including China, still enjoy developing country status in the WTO; and, second, failures to enforce the adequate protection of intellectual property (an issue on which the EU recently joined the US and filed a complaint at the WTO against Chinese practices; see European Union, 2018). These grievances, and others concerning subsidies or investment, are not new: they were clearly spelled out by policymakers from the Obama administration (see for example, Schwab, 2011, and Wu, 2016). The underlying concern is that the systemic convergence on a market economy template that was expected from participation in the WTO has failed to materialise. The rules and institutions of global trade have brought shallow convergence but not the deeper alignment of economic systems that was hoped for.

More generally, existing rules and institutions were conceived for a different world. This is very apparent in the trade field: the GATT/WTO framework dates from what Baldwin (2016) has called the "first unbundling" of production and consumption. They were not designed for the "second unbundling" of knowledge and production that gave rise to the emergence of global value chains. For decades, the implicit assumption behind the structure of trade negotiations has been that nations have well-defined sectoral trade interests: they are either exporters or importers. But in a world of global value chains, they are both importers and exporters of similar products simultaneously. Even if the principles of multilateralism remain valid, important features of the rules and institutions in which they are embedded are increasingly outdated.

In the same way, opening to capital movements was supposed to result in net financial flows from savings-rich to savings-poor countries. What has happened instead is a massive increase in gross flows resulting in the interpenetration of financial systems and the coexistence of sizeable external assets and liabilities. The consequence has been the emergence of a global financial cycle (see for example Rey, 2017) and of policy dilemmas that are quite dif-

6 The point is best understood in the context of a two-country Dornbusch-Fischer-Samuelson (1977) model of Ricardian trade with a continuum of goods: technological catching-up by the less advanced country erodes the comparative advantage of the advanced country and may reduce its gain from trade. 
ferent from those arising in a simple Mundell-Fleming framework, in which interdependence takes place through net inflows and outflows of capital.

Developments in the climate field further illustrate the point. The 1997 Kyoto Protocol was negotiated under the assumption that the bulk of greenhouse gas emissions would continue to originate in the advanced countries. But by the time the Protocol was meant to enter into force, it was clear already that the hypothesis was deeply wrong. The exemption of developing countries from emissions reductions was one of the reasons why the US did not ratify the treaty. The failed Copenhagen agreement of 2009 was an attempt to replicate Kyoto on a global scale, but there was no consensus for such an approach.

Rules can be reformed and institutions can adapt. But this is a long and demanding process, especially when it requires unanimity, when participating countries have diverging interests and when changes require ratification by parliaments where there is no majority to support them. Global rules therefore exhibit a strong inertia that often prevents necessary adaptations. Trade rules, amendments to which require unanimity, are a case in point.

Institutions are nimbler and can adapt to changing priorities or perspectives on interdependence. The IMF for example has succeeded in adjusting to major changes in the international economic regime and major shifts in the intellectual consensus. But even institutions face limitations to their ability to keep up with underlying transformations. This is one of the reasons why solutions to emerging problems have often been looked for outside the existing multilateral, institution-based governance framework (Table 1).

\section{Table 1: Global governance responses to changing global challenges}

\begin{tabular}{|c|c|c|c|}
\hline Field & $\begin{array}{l}\text { Changes over last } \\
25 \text { years }\end{array}$ & $\begin{array}{l}\text { Attempted multilateral } \\
\text { responses }\end{array}$ & Alternative responses \\
\hline $\begin{array}{l}\text { Trade and } \\
\text { investment }\end{array}$ & $\begin{array}{l}\text { Mobility of } \\
\text { technology, rise of } \\
\text { global value chains }\end{array}$ & $\begin{array}{l}\text { Failed Doha round } \\
\text { Failed MAI attempt }\end{array}$ & $\begin{array}{l}\text { Bilateral / regional } \\
\text { treaties } \\
\text { Club arrangements }\end{array}$ \\
\hline Finance & $\begin{array}{l}\text { Increased intensity } \\
\text { of sudden stops } \\
\text { Emergence of } \\
\text { global financial } \\
\text { cycle }\end{array}$ & $\begin{array}{l}\text { Failed attempt to } \\
\text { broaden IMF mandate } \\
\text { Monitoring offinancial } \\
\text { stability, coordinated } \\
\text { regulatory initiatives }\end{array}$ & $\begin{array}{l}\text { Financial protectionism, } \\
\text { self-insurance, } \\
\text { regionalism }\end{array}$ \\
\hline Competition & $\begin{array}{l}\text { Concentration on } \\
\text { global scale }\end{array}$ & None & $\begin{array}{l}\text { Extraterritorial reach } \\
\text { of national competition } \\
\text { authorities }\end{array}$ \\
\hline $\begin{array}{l}\text { Climate } \\
\text { change }\end{array}$ & $\begin{array}{l}\text { Emergence as major } \\
\text { global concern }\end{array}$ & $\begin{array}{l}\text { Failed Kyoto Protocol } \\
\text { among advanced } \\
\text { countries } \\
\text { Failed Copenhagen } \\
\text { conference }\end{array}$ & $\begin{array}{l}\text { Agreement on voluntary } \\
\text { contributions (Paris } \\
\text { agreement) }\end{array}$ \\
\hline Data & $\begin{array}{l}\text { Exponential } \\
\text { increase of flows, } \\
\text { emergence of global } \\
\text { platforms }\end{array}$ & Mere consultations & $\begin{array}{l}\text { Prevalence of industry } \\
\text { standards } \\
\text { ]Emergence of national } \\
\text { regulations } \\
\text { Risk of increasing } \\
\text { fragmentation }\end{array}$ \\
\hline
\end{tabular}

Source: Bruegel. 


\section{The imbalances of global governance}

A further reason for popular dissatisfaction with global governance is its unbalanced nature. The deeper international integration becomes, the broader the scope of policy its management should cover, and the more acute the tension between the technical requirements of global interdependence and the domestically-rooted legitimacy of public policies. This is most apparent in the field of taxation. International tax optimisation by multinationals has become an issue of significant relevance and it is estimated that 40 percent of their profit is being artificially shifted to low-tax countries - with major consequences for national budgets (Tørsløv et al, 2018). But the fact that taxation remains at the core of sovereign prerogatives limits the scope and ambition of initiatives conducted at international level. The result, which can be regarded as an illustration of Rodrik's trilemma, is that global coordination in tax matters falls short of what equity-conscious citizens regard as desirable and, at the same time, exceeds what sovereignty-conscious citizens consider acceptable.

The imbalances of global governance are by no means limited to the taxation field. The same can be found in a series of domains, for example biodiversity and the preservation of nature.

\section{E. Increased complexity}

The final obstacle to multilateral solutions has to do with the sheer complexity of the challenges global governance has to tackle. In recent decades channels of international interdependence have both multiplied and diversified. They now link together countries with significantly differing levels of technical, economic or financial development. Because they have developed outside the scope of negotiated rules and established institutions, some of channels of interdependence also escape the reach of international agreements to an unprecedented degree. This is especially, but not only, the case of the internet and the multiple networks that rely on it. The world does not fit anymore the usual representation whereby individual nations trade goods, capital and technology. Even putting aside geopolitical consequences and assuming a shared commitment to openness and multilateral solutions, such complexity is bound to test the limits of existing international governance arrangements.

\section{Global governance beyond the standard model}

\section{The gridlock calls into question the idea of broadening the scope of the traditional model beyond its core remit, and it calls for alternatives, either as substitutes for obsolete arrangements or to address emerging collective action problems in new, inadequately covered fields.}

The pervasive gridlock affecting the traditional global governance approach does not imply that existing rules are condemned to oblivion - although this could happen - or that existing institutions are bound to lose effectiveness - although some certainly will. Even in a very pessimistic scenario, the demise of the international order is likely to be slow and uneven. But at the very least, the gridlock calls into question the idea of broadening the scope of the traditional model beyond its core remit, and it calls for alternatives, either as substitutes for obsolete arrangements or to address emerging collective action problems in new, inadequately covered fields.

With little political capital to invest in the creation or the reform of universal multilateral arrangements, the problem in a nutshell is to determine if and when to rely on alternative governance arrangements. To offer a proper substitute, such arrangements would need to accommodate increased diversity amongst players, while avoiding requiring the same levels of commitment from participating countries. Or they could combine governmental and non-governmental dimensions. But they should nevertheless deliver results. Responding to this problem requires both precise analysis of the obstacles that prevent collective action in each field, and insights derived from concrete experience.

We are already witnessing an evolution towards softer, more voluntary and flexible forms

Policy Contribution | Issue n ${ }^{\circ} 17$ | October 2018 
of cooperation. Emerging governance formats are frequently not universal, but regional or partial; not treaty-based, but reliant on ad-hoc voluntary cooperation; not institution-supported, even though existing institutions can provide technical advice; not or only partially legally enforceable; less Westphalian than traditional cooperation used to be, as subnational and private players take part in them; and even sometimes not public. The keywords are voluntary commitment, flexibility and variable geometry. To name just a few fields:

- Deep trade and integration agreements increasingly involve 'coalitions of the willing', either on a regional basis or according to their specialisation;

- Investment agreements are exclusively bilateral;

- The coexistence of national competition authorities whose reach extends beyond borders, for example in the case of merger controls, is managed through agreement on shared principles, bilateral consultations and a loose coordination network;

- Whereas the IMF was initially conceived as a single financial safety net for the world, and functioned as such for several decades, regional financial safety nets have been created in Europe, Asia and Latin America. The euro area is on the verge of equipping itself with a fully-fledged 'European Monetary Fund';

- Almost all countries have taken part in the Paris agreement on climate change, but on the basis of freely-chosen commitments rather than common legally binding obligations;

- Banking regulation initiatives launched in the aftermath of the Great Financial Crisis are rooted in the 28-member Basel Committee on Banking Supervision. Implementation of the corresponding standards is being monitored, but is not mandatory;

- Tax cooperation agreements concluded within the framework of the Base Erosion and Profit Shifting (BEPS) initiative launched by the OECD involve subsets of countries and tax jurisdictions (such as the Isle of Man or the British Virgin Islands). Membership of BEPS is not universal (a number of Latin American, African and Asian countries do not take part) and not all members participate in all cooperation agreements.

Some of these arrangements are treaty-based, such as the regional trade agreements. Some are informal, such as the Paris Agreement on climate change mitigation. Some involve binding commitments; some are based on mere pledge-and-review mechanisms. Some involve states only; some involve, formally or informally, infranational players such as subnational governments and cities. Outcomes are often determined by the balance and interplay between national interests, but also by the cross-country interaction between players of different nature: scientific communities, NGOs, private corporations and subnational governments all play their parts alongside sovereign states.

The analytical and policy question is, can such flexible cooperation succeed? Can coalitions or groups effectively address problems of a global character? Can analytical consensus be reached and sustained between a series of independent players? How are externalities dealt with? Can informal arrangements overcome the free-rider curse which is pervasive in international cooperation? Can enforcement be ensured? Hard questions of this type should not be avoided, because experience shows that goodwill is not sufficient to overcome the many problems involved in international cooperation.

To this series of questions, the usual game-theory-based approach suggests a sceptical response. Externalities cannot be tackled by goodwill only, and it is not by accident that the post-second world war regime was based on universal rules, nearly universal membership in international institutions and often precise enforcement mechanisms. By contrast, it is striking how frequently contemporary international cooperation arrangements seem to rely on an excessively casual treatment of externalities.

A priority for research and public policy is therefore to find out through what mechanisms these arrangements are expected to operate (how they work in theory), to analyse concretely whether they deliver results (how they work in practice), and to determine whether and under what conditions they can form the basis of an emerging global governance model. In 
particular, the challenges they face should be investigated, and whether they address these challenges in a coherent way.

Ideas put forward by practitioners or international relation scholars are often suggestive, but fail to convince that such issues are dealt with systematically enough. To take only two examples, the "sovereign obligation" concept put forward by Haass (2017) to highlight the duties of sovereign states to their neighbours and partners in an interconnected world and the "creative coalition" concept proposed by the Oxford Martin Commission for Future Generations led by Pascal Lamy (Oxford Martin Commission, 2013), belong to two opposite traditions but share the absence of a systematic treatment of participation incentives and enforcement challenges. The same issue arises in the Westphalian world of Haass and the post-Westphalian world of Lamy: how do participants overcome the collective-action problem? Though both approaches suggest ways to overcome the global governance gridlock, neither offers a compelling solution to the participation and enforcement challenges involved in any joint endeavour.

To address these issues, the game-theoretical approach of international interdependence and collective action (see eg Sandler, 2004) provides a useful starting point. A key result from it is that interaction models and corresponding game structures vary from issue to issue, which implies that incentives to cooperate can differ substantially depending on the field. Obstacles to successful cooperation are pervasive, but not systematically as decisive as suggested by oversimplified models. Reliance on a prisoners' dilemma structure to represent the nature of the underlying game can be misleading, if the underlying game resulting from the nature of interactions between players is of a different nature. Some other games indeed result in stronger incentives to cooperate and result in more stable outcomes: assurance (also called stag hunt) games or weakest-link games raise collective action issues but do not involve the same difficulties as the prisoners' dilemma. It might be enough, in order to ensure that the cooperative equilibrium prevails, to build trust among players and to ensure a minimum degree of transparency ${ }^{7}$.

Financial stability is a good example. All countries share an interest in it because the fallout from bank failures is first and foremost national. In an interconnected world, participants however need assurance that their partners share the same concern. It is a bit like fighting fires along a border between two properties: each of the two neighbours has a strong incentive to contribute, and has no reason to be tempted to free-ride, unless one knows that her best efforts will be frustrated because the other does not care.

Furthermore, the simple two-player, static model that is so useful for presentational purposes should not be taken at face value when attempting to represent concrete international cooperation issues. For example, the underlying logic of the Paris agreement on climate change cannot be understood in a static setting. It only makes sense in a dynamic setting involving competition between a 'dirty' and a 'clean' technology (see Acemoglu et al, 2012). In such a model, the goal of an agreement is not to internalise the static externality arising from the emission of greenhouse gases - something that would require compulsion in one form or another - but to trigger a critical mass of initiatives that creates sufficient incentives for private players to invest in the development of the clean technology, so that it can eventually overtake the efficiency of the dirty technology, or at least require much less subsidy than in a static setting.

A valuable template for analysing international governance arrangements is provided by Elinor Ostrom's work on the social arrangements through which human societies tackle local externalities. Ostrom's (2009) major contribution was to show that, whereas economists regard market-driven interactions and state interventions as the only two alternatives, there are actually many possible social arrangements to manage local public goods. In her words, "the most important lesson for public policy analysis derived from [my] intellectual journey is that humans have a more complex motivational structure and more capability to solve social dilemmas than posited in earlier rational-choice theory" (Ostrom, 2009: 435). Accordingly, she

7 This is an example of the dangers of relying on powerful but excessively simplified models that provide a compelling but often misleading image of the mechanisms at work and the policy challenges. 
considered that there was a need "to ask how diverse polycentric institutions help or hinder the innovativeness, learning, adapting, trustworthiness, levels of cooperation of participants, and the achievement of more effective, equitable, and sustainable outcomes at multiple scales" (Ostrom, 2009: 436).

A similar research agenda applies to global governance: there is a need to examine systematically - and critically - the variety of arrangements at work among nations or subnational entities to find out what categories of problem they are dealing with, what the underlying interactions are, which game structures are at play, who the relevant players are and, on this basis, how effective are the mechanisms they rely on. This examination should take into account (Figure 1):

- The nature of interactions between players, the corresponding game structure and the resulting incentives to cooperate and deliver on commitments to cooperate;

- The number and diversity of players, in terms of size, influence and preferences;

- The attributes on the basis of which players read and understand their mutual interaction, such as the role of epistemic communities in building a common knowledge base and overcoming the obstacles to cooperation that arise from different representations of reality;

- And, finally, the way institutions influence individual behaviour, either through enforcing common rules or by providing assessments and monitoring of individual behaviour.

\section{Figure 1: Building blocks for the analysis of global governance issues}

\section{Institutions:}

Membership, rules, decision-making, assessment, enforcement
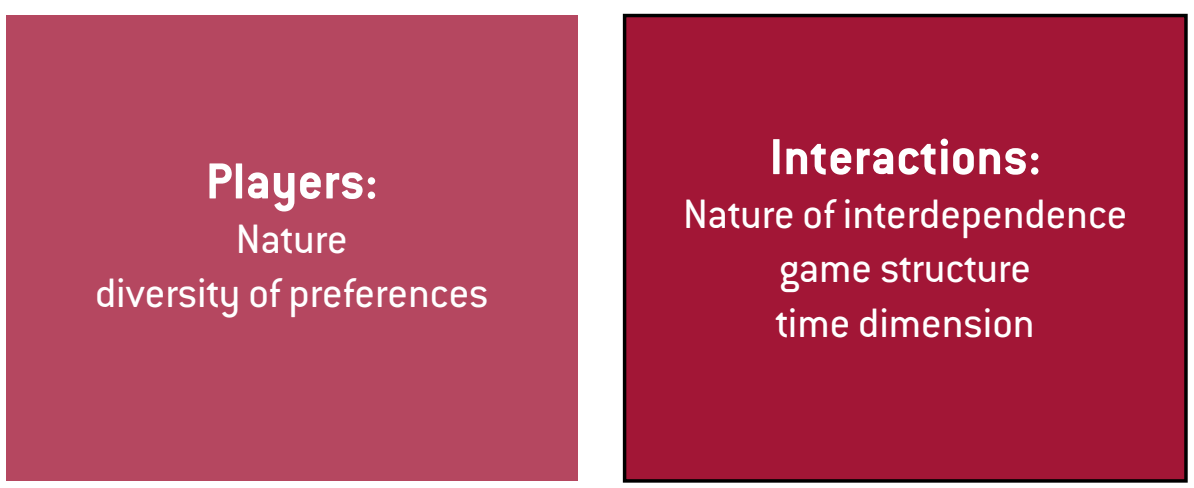

\section{Attributes}

Beliefs, knowledge, commiment, trust

Source: Bruegel.

The analytical value of such a research agenda would be to help understand how and why different types of governance arrangements adequately address different types of collective action problems. More precisely, it should help map a limited set of governance templates onto a limited set of collective action games and a wider set of concrete international cooperation issues. Here again, Ostrom (2005) provided a telling analogy when she set herself the goal of digging "below the immense diversity of regularised social interaction [...] to identify universal building blocks used in crafting such structured interactions". The diversity of regularised international interactions patterns is most likely to be less immense than that of interactions within societies, but the challenge is very similar. 


\section{Policy implications}

The outright rejection by President Trump of most of the fundamental principles of multilateralism, his decision to roll out an overly protectionist agenda, his choice to withdraw from the Paris agreement on climate change and his openly defiant attitudes towards international forums and institutions have triggered a major crisis in international economic relations. The rest of the world is witnessing with incredulity the destruction by its main creator of the post-second world war international order.

Even before President Trump took office, however, this order was already crumbling. Disappointment and setbacks followed the mid-1990s high point of international cooperation. In trade, investment, finance, the environment and a number of other fields, gridlocks, stalemates and rollbacks were observable. Geopolitical tensions, widespread second thoughts on globalisation, increasingly outdated features of international rules and institutions, the contradictory character of global governance and the sheer complexity of the problems the international community was confronted with, all contributed to this state of affairs. Already before Trump, the future of global governance was grim.

The tension between the pressing and often urgent need for global collective action and the increasing reluctance of sovereignty-conscious nations to cede competence, enter into binding agreements or abide by rules has rarely been so blatant. It is compounded by accumulated mutual mistrust, disputes over the governance of international institutions and growing rivalry between incumbents and emerging powers. Equally challenging is the complexity of a web of interdependence that involves countries of highly unequal development levels, state and subnational authorities, as well as public and private players.

Whoever sits in the White House, this tension will not vanish. It might even grow further. A lasting paralysis of the system of rules and institutions on the basis of which interdependence has been organised and managed for many decades is likely. Furthermore, there is a real risk of economic fragmentation and severe mismanagement of the global commons.

The global community, or what remains of it, visibly hesitates over the choice of strategy. A first option is 'conservationist'. It consists of preserving the existing order to the greatest extent possible. This was for example the approach followed by the remaining members of the Trans Pacific Partnership (TPP) after the US decided to withdraw in early 2017: they agreed in March 2018 to form a TPP-11 without the US. This has also been the attitude of the signatories of the 2015 Paris Agreement on climate change, again after the US withdrawal: they decided to go ahead anyway.

The advantages of the 'conservationist' strategy are to contain the damage resulting from

To the extent the US attitude is a symptom, the 'conservationist' strategy does not tackle the disease. one country's peculiar behaviour and to strengthen the other countries' ownership of the multilateral system. It furthermore sets a precedent because if it can be successfully applied to the US, it has a chance of being effective with other countries. Its downside, however, is that it does not address the underlying problems. To the extent the US attitude is a symptom, the 'conservationist' strategy does not tackle the disease. It is also unable to provide a solution to situations of potential stalemate in institutions where the US holds a blocking minority. It could in fact be defeated, at great cost to the international order.

An alternative option is to try to turn the current crisis into an opportunity to redesign international arrangements. Such a strategy would have the advantage of learning the lessons from the exhaustion of traditional multilateral agreements and institutions, and of experimenting afresh with new forms of cooperation for a different world. It would lead to the embrace of informality and flexibility, and whatever form of partial, variable-geometry and non-binding form of cooperation looks available. As indicated, there is already much experience from which to take lessons in this regard.

The downside of this option, however, would be to overlook the intrinsic problems of international or global collective action and to believe too easily that flexibility and goodwill can tackle hard problems. What has been experienced so far is in fact flexibility on the margin through, for example, regional or sectoral trade agreements on the margin of the WTO frame- 


Flexibility could
provide an alternative
to governance
through a series of
universal sectoral
institutions. It
should be seen as
a way to promote
collective action in a
context of increased
multipolarity and
diversity

Flexibility could to governance through a series of universal sectoral institutions. It should be seen as a way to promote collective action in a multipolarity and diversity work, or regional financing arrangements on the margin of the IMF framework. To tilt the balance further towards flexibility would soon lead to an entirely different game, where the multilateral framework no longer provides the overarching architecture of cooperation.

For the flexibility strategy to work and deliver results, it is not sufficient to embrace variable geometry or to minimise demands on state sovereignty. It is essential to design parsimonious arrangements that make the most of limited engagement on the part of the main nations and enlist non-state players to the greatest extent possible. The goal should be to find out how best to tackle economic, financial, environmental and technological interdependence in a world that is reluctant to relinquish political independence - and in which states are far from being all-powerful.

A potentially more promising approach than either of these two strategies would be to define the minimal conditions that the multilateral framework must fulfil to provide a strongenough basis for flexible, variable-geometry and possibly informal arrangements. With such 'critical multilateralism, a minimum set of universal principles and nimble global institutions would support collective action in a series of fields, each of which relying on specific, variable-geometry and incentive-compatible arrangements.

Understood in this way, flexibility could provide an alternative to governance through a series of universal sectoral institutions. It should be seen as a way to promote collective action in a context of increased multipolarity, increased diversity and increased concerns over infringements of national sovereignty. The need for a new approach that makes room for flexibility and cooperation between various institutions functioning as a network is increasingly recognised (Emininent Persons Group, 2018).

Such principles and institutions do exist. For example, the fundamental principles of the General Agreement on Tariffs and Trade (GATT), such as national treatment and the most-favoured nation clause, provide a basis for designing sector-specific or region-specific trade and investment arrangements. In the same way, the IMF is an example of a nimble institution whose scope and modus operandi have evolved considerably over time, despite largely unchanged articles of agreement. It has been able to support the G20 despite its informal character.

The design of flexible arrangements would require for each particular topic a determination of the channels of interdependence, the incentives and disincentives to cooperation, and the critical mass of participants that would be sufficient to create a bandwagon effect. Again, the balance between formal obligations and non-mandatory objectives does not need to be the same across domains, because externalities and participation incentives differ.

In the end, we should neither cultivate the nostalgia of yesterday's order nor invest our hopes in loose, ineffective forms of international cooperation. The narrow path ahead, if there is one, is to establish a sufficient, critical multilateral base for flexible arrangements and to equip policymakers with a precise toolkit for determining, on a field-by-field and topic-bytopic basis, the minimum requirements of effective collective action. The precise definition of such an agenda requires intellectual, institutional and political investment. There is no time to lose. 
Acemoglu, Daron, Philippe Aghion, Leonardo Bursztyn and David Hemous (2012) 'The Environment and Directed Technical Change', American Economic Review 102(1):131-66

Alesina, Alberto, Ignazio Angeloni and Federico Etro (2005) 'International Unions', American Economic Review 95(3): 602-615

Allison, Graham (2017) Destined for War: Can America and China Avoid Thucydide's Trap? Mariner Books: New York

Angeloni, Ignazio, and Jean Pisani-Ferry (2012) ‘The G20: Characters in search of an author, Working Paper 2012-04, Bruegel

Autor, David, David Dorn and Gordon Hanson (2013) 'The China Syndrome: Local Labor Market Effects of Import Competition in the United States', American Economic Review 103(6): 2121-2168

Baldwin, Richard (2016) The Great Convergence: Information technology and the new globalization, Belknap/Harvard University Press

Bery, Suman (2018) 'The G20 Leaders at ten: putting the genie back in its bottle', forthcoming, Bruegel

Caballero, Ricardo, Emmanuel Farhi and Pierre-Olivier Gourinchas (2008) 'An Equilibrium Model of “Global Imbalances” and Low Interest Rates', American Economic Review 98(1): 358-93

De Gregorio, José, Barry Eichengreen, Takatoshi Ito and Charles Wyplosz (2018) 'IMF reform: The unfinished agenda', Geneva Report on the World Economy, forthcoming

Dornbusch, Rudi, Stanley Fischer and Paul Samuelson (1977) 'Comparative Advantage, Trade, and Payments in a Ricardian Model with a Continuum of Goods', American Economic Review 67(5): 823839

Eminent persons group (2018), 'Making the global financial system work for all' (Tharman report), report to the G20, October

European Union (2018) 'Request for consultations: China - Certain measures on the transfer of technology', Memorandum at the WTO, 1 June

Fernández, Andrés, Michael W Klein, Alessandro Rebucci, Martin Schindler and Martin Uribe (2016) ‘Capital Control Measures: A New Dataset', IMF Economic Review 64(3): 548-574

Goodhart, David (2017) The Road to Somewhere, C. Hurst and Co.

Haass, Richard (2010) 'The case for messy multilateralism', Financial Times, 5 January

Haass, Richard (2017) 'World order 2.0: The case for sovereign obligations', Foreign Affairs, JanuaryFebruary

Hale, Thomas, David Held and Kevin Young (2013) Gridlock: Why global cooperation is failing when we need it most, Polity Press

Ikenberry, John (2015) 'The Future of Liberal World Order', Japanese Journal of Political Science 16(3): 450-455

Ikenberry, John (2018) 'The end of liberal international order?', International Affairs 94(1): 7-23

Jin, Xin (2018) 'Why does China Advocate the Belts and Road?', China Today 24(10)

Laïdi, Zaki (2018) ‘Comment la multipolarité déconstruit le multilatéralisme’, mimeo

Olson, Mancur (1965) The Logic of Collective Action: Public goods and the theory of groups, Harvard University Press

Ostrom, Elinor (2005) Understanding Institutional Diversity, Princeton University Press

Ostrom, Elinor (2009) 'Beyond markets and states: polycentric governance of complex economic systems', Nobel Prize lecture, 8 December 
Oxford Martin Commission (2013) Now for the Long Term, Report of the Oxford Martin Commission for Future Generations, Oxford Martin School

Pence, Michael (2018) ‘Remarks on the Administration's Policy Toward China', speech at the Hudson Institute, 4 October

Pew Research (2017) Globally, People Point to ISIS and Climate Change as Leading Security Threats, Pew Research Center, August

Rey, Hélène (2017) 'The Global Financial System, the Real Rate of Interest and a Long History of BoomBust Cycles', Andrew Crockett Memorial Lecture, BIS

Rodrik, Dani (1997) Has Globalization Gone Too Far, Peterson Institute for International Economics

Rodrik, Dani (2015) ‘Premature deindustrialisation', Journal of Economic Growth 21: 1-33

Rudd, Kevin (2018), 'The United States and China - The avoidable war', Address to the US Naval Academy, Asia Society Policy Institute, 10 October.

Samuelson, Paul (2004) 'Where Ricardo and Mill Rebut and Confirm Arguments of Mainstream Economists Supporting Globalization', Journal of Economic Perspectives 18(3): 135-146

Sandler, Todd (2004) Global Collective Action, Cambridge University Press

Schwab, Susan (2011) 'After Doha: Why the Negotiations Are Doomed and What We Should Do About It', Foreign Affairs 90(3): 104-117

Tagliapietra, Simone (2018) 'The euro-mediterranean energy relationship: A fresh perspective', Policy Brief 4/2018, Bruegel

Tørsløv, Thomas, Ludvig Wier and Gabriel Zucman (2018) ‘The Missing Profits of Nations', mimeo, 5 June

Truman, Edwin (2018) 'IMF Quota and Governance Reform Once Again', PIIE Policy Brief 18-9, Peterson Institute for International Economics

US Government (2018) 'Draft framework on balancing the trade relationship between the United States of America and the People's Republic of China', mimeo

US Trade Representative, Office of the (2018) Findings of the investigation into China's acts, policies, and practices related to technology transfer, intellectual property, and innovation under section 301 of the Trade Act of 1974, 22 March

Wolf, Martin (2018) 'How the Beijing elite sees the world', Financial Times, 1 May

Wu, Mark (2016) 'The “China, Inc.” Challenge to Global Trade Governance', Harvard International Law Journal 57(2): 261-324 